\title{
R990G polymorphism of the calcium-sensing receptor and renal calcium excretion in patients with primary hyperparathyroidism
}

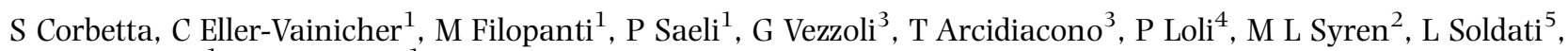 \\ P Beck-Peccoz ${ }^{1}$ and A Spada ${ }^{1}$ \\ Unità Operativa di Endocrinologia e Diabetologia, Department of Medical-Surgical Sciences, University of Milan, Policlinico San Donato IRCCS, San Donato \\ M.se, Milan, Italy, ${ }^{1}$ Endocrine Unit, Department of Medical Sciences and ${ }^{2}$ Laboratory of Medical Genetics, Institute of Pediatrics and Neonatology, \\ Fondazione Ospedale Maggiore IRCCS, University of Milan, Via F Sforza 35, 20122 Milan, Italy, ${ }^{3}$ Nephrology Unit, Postgraduate School of Nephrology, \\ San Raffaele Scientific Institute, Milan, Italy, ${ }^{4}$ Division of Endocrinology, Niguarda Hospital, Milan, Italy and ${ }^{5}$ Department of Biomedical Sciences and \\ Technology, University of Milan, Milan, Italy
}

(Correspondence should be addressed to A Spada; Email: anna.spada@unimi.it)

\begin{abstract}
Context: Primary hyperparathyroidism (PHPT) shows a great variability in clinical course and severity. Data concerning the association between polymorphic variants of the gene encoding the calciumsensing receptor (CaSR) and clinical characteristics of PHPT are not conclusive.

Objective: To evaluate the frequency of three polymorphisms; A986S, R990G, and Q1011E of CaSR in patients with PHPT and to correlate the genotypes with clinical and biochemical parameters.

Patients and methods: The study included 94 consecutive unrelated patients referred to our Departments for PHPT diagnosis and management between 2000 and 2005 and 137 age and sexmatched healthy subjects. Patients and controls were genotyped according to standard procedures. Due to the rarity of $990 \mathrm{G}$ allele, homozygous and heterozygous subjects were grouped in R/G + G/G set. All PHPT patients were studied for calcium metabolism parameters and renal and bone complications. Results: The proportion of CaSR variants was similar in PHPT patients and controls. In PHPT patients, only R990G polymorphism was associated with disease parameters; in comparison with R/R, R/G+G/G patients showed lower mean serum parathyroid hormone (PTH) and phosphate levels $(139.9 \pm 62.2 \mathrm{vs}$ $199.9 \pm 136.3 \mathrm{pg} / \mathrm{ml}, P<0.05$ and $0.69 \pm 0.12 \mathrm{vs} 0.81 \pm 0.18 \mathrm{mmol} / \mathrm{l}, P=0.031$ respectively $)$, higher mean 24-h urine calcium concentration and calcium excretion $(9.05 \pm 2.05 \mathrm{vs} 6.77 \pm 4.31 \mathrm{mmol} / 24 \mathrm{~h}$, $P=0.012$ and $67 \pm 20$ vs $51 \pm 26 \mu \mathrm{mol} / \mathrm{l} \mathrm{GF}, P=0.039$ ), and increased prevalence of nephrolithiasis (90.0 vs $44.2 \%, P=0.007$ ).

Conclusions: The study showed that patients with PHPT, bearing the $990 \mathrm{G}$ allele, had lower serum PTH levels and higher urinary calcium excretion in comparison with the other genotype, suggesting an increased sensitivity of the variant receptor to extracellular calcium. Since this variant was associated with increased occurrence of nephrolithiasis, analysis of this polymorphism might help to predict renal complication of the disease.
\end{abstract}

European Journal of Endocrinology 155 687-692

\section{Introduction}

Primary hyperparathyroidism (PHPT) is a clinical entity characterized by excessive parathyroid hormone (PTH) secretion and hypercalcemia due to parathyroid adenoma, hyperplasia or, very rarely, carcinoma, with an estimated prevalence of about $3 \%$ of post-menopausal women in Western countries. The disorder is highly heterogeneous in its clinical course and pathological severity. However, the genetic and environmental background responsible for the different clinical development of PHPT has not been completely elucidated. Previous studies investigated the association of polymorphic variants of candidate genes, such as vitamin D receptor, estrogen receptor, and PTH genes, with several biochemical and clinical parameters of the disease in Caucasian and Japanese populations (1-4).
More recently, the possibility that genetic alterations of the calcium-sensing receptor gene (CaSR), a G-proteincoupled receptor expressed in a variety of tissues, including the parathyroid, kidney, and bone, could be involved in PHPT has been the object of active investigations. Calcium binding to CaSR induces the generation of a complex series of intracellular signals, resulting in the inhibition of both PTH secretion and calcium reabsorption in the kidney thick ascending limb $(5,6)$. Clinically, inactivating mutations of the CaSR gene are responsible for familial hypocalciuric hypercalcemia and severe neonatal hyperparathyroidism, while activating mutations lead to autosomal dominant and sporadic forms of hypocalcemia (7-9). No mutations in CaSR coding sequence have been found in parathyroid tumors $(10,11)$. 
Several polymorphisms within the human CaSR gene have been described $(8,12)$. The association of three single nucleotide polymorphisms that map onto the portion of exon 7 coding for the CaSR intracellular tail, i.e. A986S, R990G, and Q1011E, with calcium and PTH levels has been extensively investigated in healthy populations (13-16) and patients with disorders of calcium metabolism (17-21). However, data concerning the possible contribution of these variants to the development of PHPT, the clinical course, and the severity of the disease are not conclusive (18-20).

The aim of the present study was to evaluate the frequency of CaSR variants and their possible association with clinical and biochemical parameters of the disease in a cohort of Italian patients with PHPT. The study showed that patients with the 990G allele as a group had lower serum PTH levels, higher urinary calcium excretion, and increased prevalence of nephrolithiasis in comparison with the other genotype.

\section{Patients and methods}

\section{Subjects}

The study included 94 consecutive unrelated Italian patients (80 females and 14 males; median age at presentation $66 \pm 12$ years) referred to our Departments between May 2000 and May 2005 for diagnosis and management of PHPT. As controls, 137 age- and sexmatched subjects recruited among subjects referred to the Outpatient Endocrinology Unit at the Fondazione IRCCS Ospedale Policlinico for euthyroid multinodular goiter $(n=40)$ and to the Outpatient Osteoporosis Clinics at the San Raffaele Hospital for osteopenia $(n=97)$. Subjects were eligible as controls if they were Caucasian, had no personal and family history of kidney stones, had normal serum creatinine, calcium and phosphate, and $24 \mathrm{~h}$ urinary calcium levels, and were not taking any drugs. Diagnosis of PHPT was made on the basis of high ionized calcium levels in the presence of elevated or inappropriately normal serum PTH levels (plasma ionized calcium $1.51 \pm 0.15 \mathrm{mmol} / \mathrm{l}(1.31-1.99)$, n.v. $1.15-1.29 \mathrm{mmol} / \mathrm{l}$; total serum calcium $2.84 \pm$ $0.23 \mathrm{mmol} / \mathrm{l}$ (2.35-3.60), n.v. $2.20-2.60 \mathrm{mmol} / \mathrm{l}$; serum PTH $192 \pm 131$ (40-1000), n.v. 10-65 pg/ml, mean \pm s.D. (range)) and confirmed by surgery in patients who underwent parathyroidectomy $(n=38)$ according to the NIH consensus (22). No patient had positive familial history for PHPT or were known to be affected with familial benign hypocalciuric hypercalcemia, multiple endocrine neoplasia syndrome type 1 (MEN 1), and hyperparathyroidism jaw tumor syndrome (HPTJT). All patients had normal serum creatinine. Systolic and diastolic blood pressures (SBP and DBP) were measured according to the World Health Organization (WHO) International Society of Hypertension Guidelines. Arterial hypertension (SBP> 85 and $\mathrm{DBP}>135 \mathrm{mmHg}$ ) was present in $55.2 \%$ of the patients. Anti-hypertensive therapy was modified in order to avoid administration of diuretics, with a wash-out period of at least 3 months. Nephrolithiasis, defined as a history of renal colic with stone expulsions and/or imaging identification or asymptomatic ultrasound imaging of stones, was identified in $46.5 \%$ of the patients. Osteoporosis, defined as a T-score lower than -2.5 at least in one of the sites evaluated with dual energy X-ray absorptiometry (DEXA) at femur and lumbar spine level, was present in $55 \%$ of the patients. No patients had been taking anti-fracture drugs (bisphosphonates or vitamin D) in the 3 months preceding the study.

The study complies with the Helsinki Declaration and was approved by the local Ethical Committee (Fondazione IRCCS Ospedale Maggiore Policlinico, Mangiagalli e Regina Elena, Milan, Italy) All participants signed an informed consent form, which included consent for genetic testing.

\section{Laboratory tests}

Venous blood samples after overnight fasting were obtained from all patients under a free diet for measurement of ionized calcium, total calcium, phosphate, intact PTH, and creatinine, as previously reported (23). Plasma ionized calcium was measured by a potentiometric method (Radiometer ABL System 625, Copenhagen, Denmark) on heparinized blood samples within 30 min from blood collection. Serum intact PTH was measured by a chemiluminescent method (Nichols Institute Diagnostics, San Juan Capistrano, CA, USA), with an intra- and interassay coefficients of variation of $<4.5$ and $<10.0 \%$ respectively. Serum 1,25 dihydroxyvitamin D3 was assayed by RIA kit (Immunodiagnostic Systems Limited, Boldon, UK), with an intra- and interassay coefficients of variation of $<8$ and $<10 \%$ respectively. Calcium, phosphate, and creatinine were measured in $24 \mathrm{~h}$ urine collections (from $0700 \mathrm{~h}$ of the day before to $0700 \mathrm{~h}$ of the examination day) in 79 patients. Calcium excretion was expressed as a function of glomerular filtrate (GF) according to the formula reported by Fuleihan et al. (24) and the values expressed as $\mu \mathrm{mol} / \mathrm{l}$ GF. Tubular maximal phosphate (TmP) reabsorption was calculated according to Walton and Bijvoet nomogram (25). All patients underwent an ultrasound examination of the urinary tract. All had bone mineral density evaluation by DEXA of the lumbar spine L2-L4 and the proximal femur (femoral neck).

\section{DNA extraction and genotyping}

Blood genomic DNA was extracted according to the standard procedures (26). PCRs were carried out in a $50 \mu \mathrm{l}$ reaction mix with $0.5 \mu \mathrm{g}$ DNA, $25 \mathrm{pmol}$ of each primer, and $2.5 \mathrm{U}$ Taq DNA polymerase AmpliTaq (Perkin-Elmer Corp., Foster City, CA, USA), denaturated at $95^{\circ} \mathrm{C}$ for $3 \mathrm{~min}$, followed by 35 cycles at $95^{\circ} \mathrm{C}$ for 
Table 1 Frequency of A986S, R990G and Q1011E variants in 94 patients affected with primary hyperparathyroidism and 137 age and sex-matched normal subjects.

\begin{tabular}{llccc}
\hline \multirow{2}{*}{ Codon } & & Patients $(n=94)$ & Controls $(n=137)$ & \\
& & $n$ & $n$ & $\boldsymbol{P}$ \\
\hline \multirow{4}{*}{986} & $\mathrm{~A} / \mathrm{A}$ & 58 & 91 & \\
& $\mathrm{~A} / \mathrm{S}$ & 28 & 42 & 0.16 \\
& $\mathrm{~S} / \mathrm{S}$ & 8 & 4 & \\
990 & $\mathrm{R} / \mathrm{R}$ & 83 & 128 & \\
& $\mathrm{R} / \mathrm{G}$ & 9 & 8 & 0.36 \\
& $\mathrm{G} / \mathrm{G}$ & 2 & 1 & \\
\multirow{4}{*}{1011} & $\mathrm{Q} / \mathrm{Q}$ & 89 & 123 & \\
& $\mathrm{Q} / \mathrm{E}$ & 5 & 14 & 0.18 \\
& $\mathrm{E} / \mathrm{E}$ & 0 & 0 & \\
\hline
\end{tabular}

$1 \mathrm{~min}, 54{ }^{\circ} \mathrm{C}$ for $1 \mathrm{~min}, 72{ }^{\circ} \mathrm{C}$ for $1 \mathrm{~min}$, and a final cycle at $72{ }^{\circ} \mathrm{C}$ for $10 \mathrm{~min}$. The primer pairs were $5^{\prime}$-GCAAGCAGAAGGTCATCTTT- $3^{\prime}$ and $5^{\prime}$-GTCCTTGCAGACCTGTTTC-3'. PCR products were sequenced by ABI-PRISM sequencer.

\section{Statistical analysis}

We reported quantitative variables in the text as mean \pm S.D. Differences among means were tested by $t$-test, or one-way ANOVA with Bonferroni post-test where data were normally distributed. Otherwise, Mann-Whitney rank sum test was performed. $\chi^{2}$ analysis was used to test differences in allele frequencies between patients and controls. Fisher's exact test was applied whenever expected values were $<5$. Two-tailed $P$ value $<0.05$ was considered statistically significant.

\section{Results}

Healthy subjects and patients with PHPT showed a similar proportion of A986S, R990G, and Q1011E genotypes. In particular, A986S was the most recurrent polymorphism and A986, R990, and Q1011 the most frequent alleles in both groups of subjects (Table 1). Homozygous or heterozygous patients for variant allele at codon 986 did not show significant differences in serum PTH, ionized calcium, total calcium, and phosphate levels as well as $24 \mathrm{~h}$ calcium and phosphate excretion (Table 2). Moreover, prevalence of hypertension, osteoporosis, and nephrolithiasis was similar in these genotypes (Table 3).

Due to the small number of $990 \mathrm{G}$ homozygotes, associations between 990 variants and quantitative variables were evaluated by grouping homozygous and heterozygous patients in $\mathrm{R} / \mathrm{G}+\mathrm{G} / \mathrm{G}$ set. The proportion of male patients was similar in the two groups (13/83 in $\mathrm{R} / \mathrm{R}$ and $1 / 11$, in $\mathrm{R} / \mathrm{G}+\mathrm{G} / \mathrm{G}, P=1.00$ Fisher's exact test). Serum PTH and phosphate levels were lower in $\mathrm{R} / \mathrm{G}+\mathrm{G} / \mathrm{G}$ than in $\mathrm{R} / \mathrm{R}$ groups $(139.9 \pm 62.2$ vs $199.9 \pm 136.3 \mathrm{pg} / \mathrm{ml}, P<0.05$ and $0.69 \pm 0.12$ vs $0.81 \pm 0.18 \mathrm{mmol} / \mathrm{l}, \quad P=0.031$ respectively), in the absence of significant differences in total and ionized calcium levels (Table 2). No difference in 1,25 dihydroxyvitamin D3 levels was observed (51.1 $33.0 \mathrm{pg} / \mathrm{ml}$ vs $64.0 \pm 44.8, \mathrm{R} / \mathrm{G}+\mathrm{G} / \mathrm{G}$ vs $\mathrm{R} / \mathrm{R}$ patients respectively; $P=\mathrm{NS}$ ). Moreover, $24 \mathrm{~h}$ urine calcium concentration, as well as calcium excretion, were significantly higher in $\mathrm{R} / \mathrm{G}+\mathrm{G} / \mathrm{G}$ than in $\mathrm{R} / \mathrm{R}$ patients $(9.05 \pm 2.05$ vs $6.77 \pm 4.31 \mathrm{mmol} / 24 \mathrm{~h}, \quad P=0.012$; $67 \pm 20$ vs $51 \pm 26 \mu \mathrm{mol} / \mathrm{l}$ GF, $P=0.039$; Table 2), whereas urinary phosphate concentrations and TmP values did not show significant difference between the two groups $(1.71 \pm 0.08$ in $R / G+G / G$ vs $1.76 \pm 0.06$ in $\mathrm{R} / \mathrm{R}, \mathrm{P}=\mathrm{NS}$ ). Serum creatinine and creatinine clearance did not significantly differ between the two groups of patients $(0.85 \pm 0.28 \mathrm{mg} / \mathrm{dl}$ in $\mathrm{RR}$ vs $0.85 \pm 0.22$ in $\mathrm{RG}+\mathrm{GG}, P=\mathrm{NS}$ ).

Nephrolithiasis was more common in $\mathrm{R} / \mathrm{G}+\mathrm{G} / \mathrm{G}$ than in $\mathrm{R} / \mathrm{R}$ groups ( 90.0 vs $44.2 \%, P=0.007$ ), whereas no difference in the clinical presentation was observed. The prevalence of osteoporosis (Table 3), and the severity, did not differ among R990G genotypes (lumbar T-score: $-2.1 \pm 1.6$ in $\mathrm{R} / \mathrm{R}$ vs $-2.2 \pm 1.0$ in $\mathrm{R} / \mathrm{G}+\mathrm{G} / \mathrm{G}, P=\mathrm{NS}$;

Table 2 Biochemical parameters observed in patients with primary hyperparathyroidism according to the calcium-sensing receptor (CaSR) genotypes. Serum parathyroid hormone (PTH) and ionized calcium $\left(\mathrm{Ca}^{++}\right)$, serum calcium $(\mathrm{Ca})$ and phosphorous $(\mathrm{P}), 24 \mathrm{~h}$ urinary calcium (u-Ca) and phosphorus were measured. Data are reported as mean \pm S.D.

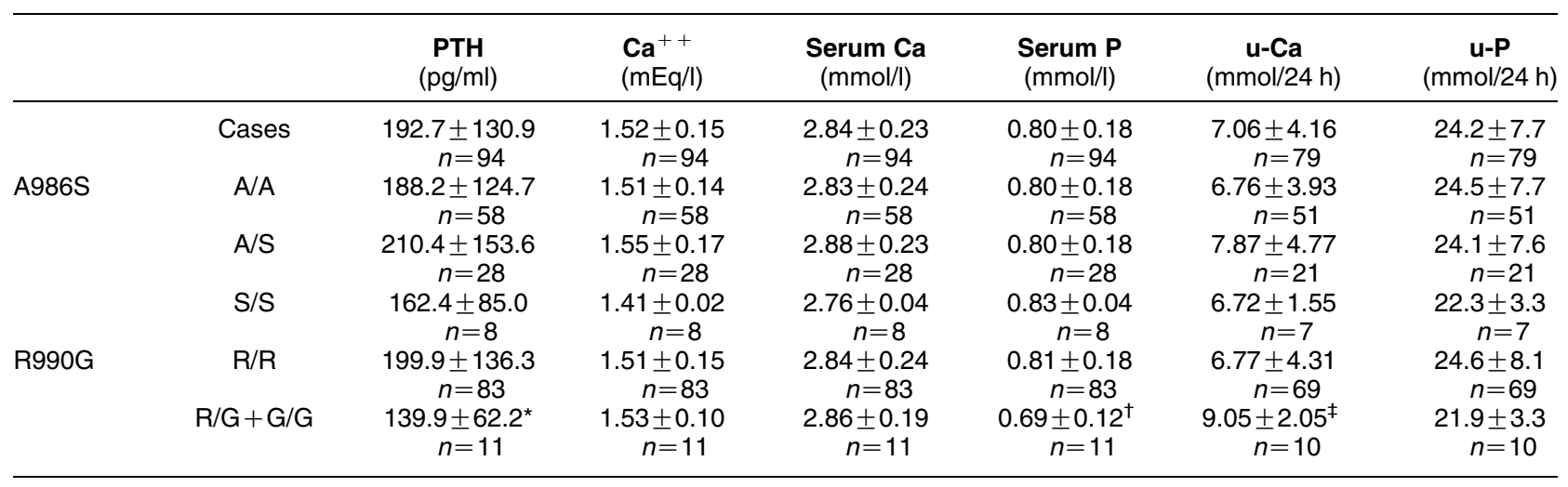

${ }^{*} P<0.05$ vs $\mathrm{R} / \mathrm{R} ;{ }^{\dagger} P=0.031$ vs $\mathrm{R} / \mathrm{R} ;{ }^{\ddagger} P=0.012$ vs $\mathrm{R} / \mathrm{R}$. 
Table 3 Hypertension, osteoporosis and nephrolithiasis proportions between CaSR A986S and R990G genotypes in patients affected with primary hyperparathyroidism. Data are reported as number of affected subjects/number of unaffected subjects.

\begin{tabular}{ccccc}
\hline & & Hypertension & Osteoporosis & Nephrolithiasis \\
\hline \multirow{3}{*}{ A986S } & $\mathrm{A} / \mathrm{A}$ & $33 / 25$ & $34 / 24$ & $30 / 24$ \\
& $\mathrm{~A} / \mathrm{S}$ & $16 / 12$ & $15 / 13$ & $12 / 14$ \\
$\mathrm{R} 990 \mathrm{G}$ & $\mathrm{S} / \mathrm{S}$ & $2 / 8$ & $3 / 5$ & $1 / 6$ \\
& $\mathrm{R} / \mathrm{R}$ & $47 / 36$ & $45 / 38$ & $34 / 43$ \\
& $\mathrm{R} / \mathrm{G}+\mathrm{G} / \mathrm{G}$ & $4 / 7$ & $7 / 4$ & $9 / 1^{*}$ \\
\hline
\end{tabular}

${ }^{*} P=0.007$ vs $\mathrm{R} / \mathrm{R}$. Arterial hypertension was defined as systolic and diastolic blood pressure $>85$ and $\mathrm{DBP}>135 \mathrm{~mm}$, respectively. Osteoporosis was defined as a $T$-score lower than -2.5 at least in one of the site evaluated with dual energy X-ray absorptiometry (DEXA) at femur and lumbar spine level. Nephrolithiasis was defined as a history of renal colic with stone expulsions and/or imaging identification or asymptomatic ultrasound imaging of stones.

femoral T-score: $-1.8 \pm 0.9$ in $\mathrm{R} / \mathrm{R}$ vs $-2.1 \pm 0.9$ in $\mathrm{R} / \mathrm{G}+\mathrm{G} / \mathrm{G}, P=\mathrm{NS}$ ). No difference in the prevalence of hypertension was observed.

Q1011E polymorphism was not analyzed due to the extremely low frequency (Table 1).

\section{Discussion}

The study provided evidence for a contribution of CaSR polymorphisms in the genetic background influencing the clinical course of PHPT. In fact, the analysis of three common CaSR missense polymorphisms encoding non-conservative amino acid changes, i.e. A986S, R990G, and Q1011E, showed an association of PTH levels, urine calcium excretion, and prevalence of nephrolithiasis with R990G polymorphism in PHPT.

Several genetic factors; polymorphic variants of vitamin D receptor, $\mathrm{PTH}$, and estrogen receptor genes, have been implicated in the development and severity of PHPT (1-4). More recently, based on in vivo and in vitro observations indicating CaSR as a key molecule for the control of PTH-calcium set point, the association between polymorphic variants of CaSR gene and parameters of calcium metabolism has been investigated in healthy subjects and in patients with PHPT (12-20). In the present study, no difference in the frequency of the three common CaSR polymorphisms between controls and patients was observed. These data are in agreement with previous data obtained in German and Italian cohorts of PHPT patients and controls matched for sex, age, and geographic provenience $(19,20)$. Therefore, the present study confirms that the three CaSR variants so far investigated do not seem to predispose to the development of PHPT.

The major aim of the present study was to investigate whether a given genotype might affect the clinical course of PHPT. In agreement with previous reports, no association between A986S polymorphism and clinical data was found $(19,20)$. By contrast, the replacement of arginine by glycine at position 990 of the CaSR was associated with a clinical phenotype. In fact, homozygous and heterozygous patients with the $990 \mathrm{G}$ allele showed lower serum PTH, higher urinary calcium excretion, and increased prevalence of nephrolithiasis in comparison with the other genotype. These data are in contrast with previous studies, which failed to find any association between R990G polymorphism and clinical course of PHPT; this discrepancy probably being due to the low number of patients included in previous series as well as the rare occurrence of 990 polymorphism in Caucasian population $(19,20)$. By contrast, the association of the variant 990G allele with lower PTH levels has been observed in patients with primary and secondary hyperparathyroidism in Japan, where this genetic variant occurs much more frequently, probably related to different ethnic and genetic backgrounds (18). Since urinary calcium excretion and occurrence of nephrolithiasis were not investigated in that study, the author's hypothesis was that R990G polymorphism might predict a less severe course of PHPT (18). The analysis of clinical parameters of the present study led to opposite conclusions, since patients with R990G polymorphism showed increased urinary calcium excretion and higher occurrence of stone formation in comparison with those homozygous for $\mathrm{R}$ at that location. The association of R990G with nephrolithiasis did not appear to be exclusive of PHPT. In fact, it has been reported that the variant $990 \mathrm{G}$ allele was more recurrent in stone-forming patients with primary hypercalciuria compared with normocalciuric stone formers or healthy individuals (21).

The calcium excess in the urine might result from either enhanced intestinal calcium absorption, increased mobilization of skeletal calcium, or increased urinary excretion. Although increased renal production of calcitriol with hyperabsorption of intestinal calcium is considered to be clinically relevant, the lack of difference in 1,25 dihydroxyvitamin D3 levels between patients harboring or not the variant 990G allele suggests that vitamin D status was not the main determinant of hypercalciuria in patients with R990G polymorphism. Moreover, the similar occurrence and severity of osteoporosis observed in patients independently from the genotype ruled out increased mobilization of skeletal calcium as a cause of hypercalciuria. These data, together with the high calcium excretion found in association with R990G polymorphism, support the view that the reduction in renal calcium reabsorption might be responsible for hypercalciuria in these patients.

Patients with R990G polymorphism showed phosphate levels lower than those found in homozygous for $\mathrm{R}$, while urine phosphate excretion as well as TmP and 1,25 dihydroxyvitamin D3 levels were similar in the two genotypes. Although no clear explanation for this unexpected finding is available, recent experiments carried out on in vitro animal models of proximal tubule cells suggested that CaSR activation may specifically inhibit the PTH-suppressible renal phosphate transport 
(27). Moreover, in addition to PTH, other peptide hormones, growth factors, and cytokines have been involved in the regulation of phosphate transport (28, 29). It is tempting to speculate that CaSR activation might influence calcium-phosphate homeostasis and particularly renal phosphate absorption by affecting these factors.

Most patients with PHPT are asymptomatic during diagnosis and a good proportion remains stable for years, without undergoing parathyroidectomy $(30,31)$. However, nephrolithiasis remains a frequent and important complication of the disease that requires interventional treatment. In this respect, the association of R990G polymorphism with stone formation might help to identify those patients who are likely to develop severe PHPT in the future and to require early therapeutic intervention. However, due to the low frequency of this variant, additional studies on large number of patients are required to make definitive conclusions.

R990G is a non-conservative polymorphism located in the CaSR carboxyl-terminal tail. It is probable that the replacement of the basic amino acid arginine by the neutral amino acid glycine may affect conformation and folding of receptor domains, thus altering the capability of CaSR to activate G-proteins and to bind filamin-A. Indeed, previous studies suggested that CaSR tail possesses determinants that impact on several properties of the receptor, such as cell surface expression, intracellular signaling activation, degree of positive co-operativity, and/or rate of desensitization $(32,33)$.

The hypothesis that $\mathrm{G}$ at position 990 might make the receptor more sensitive to calcium is supported by some clinical observations $(34,35)$. In particular, it has been reported that a moderate increase of extracellular calcium in patients with end-stage renal disease on regular hemodialysis caused a significant reduction of PTH levels only in patients bearing the 990G allele (34). Moreover, in a small series of patients with secondary hyperparathyroidism, it has been observed that subjects homozygous for $990 \mathrm{G}$ showed a more marked inhibition of PTH levels in response to treatment with the calcimimetic drug Cinacalcet compared with those homozygous for $\mathrm{R}$ at that location (35).

In conclusion, this study showed that patients with PHPT bearing the 990G allele had lower serum PTH levels and higher urinary calcium excretion in comparison with the other genotype, suggesting an increased sensitivity of the variant receptor to extracellular calcium. Since this polymorphism was associated with an increased occurrence of nephrolithiasis, analysis of this might help to predict the severity of the disease.

\section{Acknowledgements}

This work was partially supported by Ricerca Corrente Funds of Fondazione Ospedale Maggiore IRCCS and AIRC, Milan.

\section{References}

1 Carling T, Kindmark A, Hellman P, Lundgren E, Ljunghall S, Rastad J, Akerstrom G \& Melhus H. Vitamin D receptor genotypes in primary hyperparathyroidism. Nature Medicine 19951 1309-1311.

2 Kobayashi T, Sugimoto T, Kobayashi A \& Chihara K. Vitamin D receptor genotype is associated with cortical bone loss in Japanese patients with primary hyperparathyroidism. Endocrine Journal 1998 45123-45125.

3 Carling T, Rastad J, Kindmark A, Lundgren E, Ljunghall S \& Akerstrom G. Estrogen receptor gene polymorphisms in postmenopausal primary hyperparathyroidism. Surgery 1997122 1101-1106.

4 Kanzawa M, Sugimoto T, Kobayashi T, Kobayashi A \& Chihara K. Parathyroid hormone gene polymorphisms in primary hyperparathyroidism. Clinical Endocrinology 199950 583-588.

5 Chattopadhyay N, Mithal A \& Brown EM. The calcium sensing receptor: a window into the physiology and pathophysiology of mineral ion metabolism. Endocrine Review 199617 289-307.

6 Brown EM \& McLeod JR. Extracellular calcium sensing and extracellular calcium signaling. Endocrine Review 2001 81 239-297.

7 Pollak MR, Brown EM, Chou YH, Chou YH, Hebert SC, Marx SJ, Steinmann B, Levi T, Seidman CE \& Seidman JG. Mutations in the human $\mathrm{Ca}^{2+}$ sensing receptor gene cause familial hypocalciuric hypercalcemia and neonatal severe hyperparathyroidism. Cell 199375 1297-1303.

8 Lovlie K, Eiken HG, Sorheim JI \& Boman H. The $\mathrm{Ca}^{2+}$ sensing receptor gene (PCAR1) mutation T151M in isolated autosomal dominant hypoparathyroidism. Human Genetics 199698 129-133.

9 Hendy GN, D'Souza-Li L, Yang B, Canaff L \& Cole DE. Mutations of the calcium-sensing receptor (CaSR) in familial hypocalciuric hypercalcemia, neonatal severe hyperparathyroidism, and autosomal dominant hypocalcemia. Human Mutations 200016 281-296.

10 Hosokawa Y, Pollak MR, Brown EM \& Arnold A. Mutation analysis of the extracellular $\mathrm{Ca}^{2+}$-sensing receptor gene in human parathyroid tumors. Journal of Clinical Endocrinology and Metabolism 199580 3107-3110.

11 Cetani F, Pinchera A, Pardi E, Cianferotti L, Vignali E, Picone A, Miccoli P, Viacava P \& Marcocci C. No evidence for mutations in the calcium-sensing receptor gene in sporadic parathyroid adenomas. Journal of Bone and Mineral Research 199914 $878-882$.

12 Heath HIII, Odelberg S, Jackson CE, Teh BT, Hayward N, Larsson C, Buist NR, Krapcho KJ, Hung BC, Capuano G, IV, arrett JE \& Leitket MF. Clustered inactivating mutations and benign polymorphisms of the calcium sensing receptor gene in familial benign hypocalciuric hypercalcemia suggest receptor functional domains. Journal of Clinical Endocrinology and Metabolism $1996 \mathbf{8 1}$ 1312-1317.

13 Cole DEC, Peltekova VD, Rubin LA, Hawker GA, Vieth R, Liew CC, Hwang DM, Evrovski J \& Hendy GN. A986S polymorphism of the calcium-sensing receptor and circulating calcium concentrations. Lancet 1999353 112-115.

14 Lorentzon M, Lorentzon R, Lerner UH \& Nordström P. Calcium sensing receptor gene polymorphism, circulating calcium concentrations and bone mineral density in healthy adolescent girls. European Journal of Endocrinology 2001144 257-261.

15 Bollerslev J, Wilson SG, Dick IM, Devine A, Dhaliwal SS \& Prince IR. Calcium-sensing receptor gene polymorphism A986S does not predict serum calcium level, bone mineral density, calcaneal ultrasound indices, or fracture rate in a large cohort of elderly women. Calcified Tissue International $2004 \mathbf{7 4} 12-17$.

16 Scillitani A, Guarnieri V, De Geronimo S, Muscarella LA, Battista C, D’Agruma L, Bertoldo F, Florio C, Minisola S, Hendy GN \& Cole DEC. Blood ionized calcium is associated with clustered polymorphisms in the carboxyl-terminal tail of the calcium-sensing receptor. Journal of Clinical Endocrinology and Metabolism 200489 5634-5638. 
17 Yano S, Sugimoto T \& Kanzawa M. Association of polymorphic alleles of the calcium-sensing receptor gene with parathyroid hormone secretion in hemodialysis patients. Nephron $2000 \mathbf{8 5}$ 317-323.

18 Yamauchi M, Sugimoto T, Yamaguchi T, Yano S, Kanzawa M, Kobayashi A \& Chihara K. Association of polymorphic alleles of the calcium-sensing receptor gene with the clinical severity of primary hyperparathyroidism. Clinical Endocrinology $2001 \mathbf{5 5}$ 373-379.

19 Miedlich S, Lamesch P, Mueller A \& Paschke R. Frequency of the calcium-sensing receptor variant A986S in patients with primary hyperparathyroidism. European Journal of Endocrinology $2001 \mathbf{1 4 5}$ 421-427.

20 Cetani F, Borsari S, Vignali E, Pardi E, Picone A, Cianferotti L, Rossi G, Miccoli P, Pinchera A \& Marcocci C. Calcium-sensing receptor gene polymorphisms in primary hyperparathyroidism. Journal of Endocrinological Investigation 200225 614-619.

21 Vezzoli G, Tanini A, Ferrucci L, Soldati L, Bianchin C, Franceschelli F, Malentacchi C, Porfirio B, Adamo D, Terranegra A, Falchetti A, Cusi D, Bianchi G \& Brandi ML. Influence of calcium-sensing receptor gene on urinary calcium excretion in stone-former patients. Journal of the American Society of Nephrology $2002132517-2523$.

22 Potts JT (Ed.). NIH Consensus development conference statement on primary hyperparathyroidism. Journal of Bone and Mineral Research 1991 6:S9-S13.

23 Corbetta S, Baccarelli A, Aroldi A, Vicentini L, Fogazzi GB, EllerVainicher C, Ponticelli C, Beck-Peccoz P \& Spada A. Risk factors associated to kidney stones in primary hyperparathyroidism. Journal of Endocrinological Investigation 2005 28 122-128.

24 Fuleihan GE, Seifter J, Scott J \& Brown EM. Calcium-regulated renal calcium handling in healthy men: relationship to sodium handling. Journal of Clinical Endocrinology and Metabolism $1998 \mathbf{8 3}$ 2366-2372.

25 Walton RJ \& Bijvoet OLM. Nomogram for derivation of renal threshold phosphate concentration. Lancet 197516 309-310.

26 Filopanti M, Ronchi C, Ballarè E, Bondioni S, Lania AG, Losa M, Gelmini S, Peri A, Orlando C, Beck-Peccoz P \& Spada A. Analysis of somatostatin receptors 2 and 5 polymorphisms in patients with acromegaly. Journal of Clinical Endocrinology and Metabolism 2005 $904824-4828$.
27 Ba J, Brown D \& Friedman PA. Calcium-sensing receptor regulation of PTH-inhibitable proximal tubule phosphate transport. American Journal Physiology - Renal Physiology 2003285 1233-1243.

28 Prie D, Beck L, Urena P \& Friedlander G. Recent findings in phosphate homeostasis. Current Opinion in Nephrology and Hypertension 200514 318-324.

29 Kobayshi K, Imanishi Y, Miyauchi A, Oneda N, Kawata Y, Tahara H, Goto H, Miki T, Ishimura E, Sugimoto T, Ishikawa T, Inaba M \& Nishizawa Y. Regulation of plasma fibroblast growth factor 23 by calcium in primary hyperparathyroidism. European Journal of Endocrinology $2006 \mathbf{1 5 4} 93-99$.

30 Bilezikian JP, Silverberg SJ, Shane E, Parisien M \& Dempster DW. Characterization and evaluation of asymptomatic primary hyperparathyroidism. Journal of Bone and Mineral Research 1991 (Suppl 2) S85-S89.

31 Silverberg SJ, Shane E, Jacobs TP, Siris E \& Bilezikian JP. A 10-year prospective study of primary hyperparathyroidism with or without parathyroid surgery. New England Journal of Medicine $19993 \mathbf{3 4}$ 1249-1255.

32 Gama L \& Breitweiser GE. A carboxyl-terminal domain controls the cooperativity $\mathrm{Ca}^{2+}$ activation of the human calcium sensing receptor. A study with receptor-green fluorescent protein fusions. Journal of Biological Chemistry 1998273 29712-29718.

33 Hjalm G, MacLeod RH, Kifor O, Chattopadhyay N \& Brown EM. Filamin-A binds to the carboxyl-terminal tail of the calciumsensing receptor, an interaction that participates in CaR-mediated activation of mitogen-activated protein kinase. Journal of Biological Chemistry 2001276 34880-34887.

34 Yokoyama K, Shigematsu T, Tsukada T, Hara S, Yamada S, Kawaguch Y \& Hosoya T. Calcium-sensing receptor gene polymorphism affects the parathyroid response to moderate hypercalcemic suppression in patients with end-stage renal disease. Clinical Nephrology 200257 131-135.

35 Rothe HM, Shapiro WB, Sun WY \& Chou S-Y. Calcium-sensing receptor gene polymorphism $\mathrm{R} 990 \mathrm{G}$ and its possible effect on response to cinacalcet HCl. Pharmacogenetics and Genomics 200515 29-34.

Received 12 June 2006

Accepted 30 August 2006 